\title{
PReS-FINAL-2210: Qualitative aspects of autoinflammatory diseases
}

\author{
D Konukbay ${ }^{1 *}$, D Yildiz ${ }^{1}$ C C Acikel ${ }^{2}$, D Karaman ${ }^{3}$, B Fidanci $^{1}$, Y Bilginer ${ }^{4}$, I Kone-Pau ${ }^{5}$, J Frenkel ${ }^{6}$, M Gottorno $^{7}$, \\ S Ozen ${ }^{4}$, E Demirkaya ${ }^{8}$ \\ From 20th Pediatric Rheumatology European Society (PReS) Congress \\ Ljubljana, Slovenia. 25-29 September 2013
}

\section{Introduction}

In pediatric rheumatology, the lack of scales showing activities of illness in the patients groups, the absence of biomarkers for the severity of damage led the scientific world to develop a scale where the patient can make an selfassessment with quantitative results. So, a necessity has been occurred to develop a multidimensional scale which is understandable, applicable and comprehensive in the evaluation of children with auto-inflammatory diseases.

\section{Objectives}

The aim of this study is to develop a multidimensional assessment instrument named "Juvenile Autoinflammatory Disease Multidimensional Assessment Report" (JAIMAR) to measure all the domains of the autoinflammatory diseases. In this study the data of "Qualitative Interviews", one of the steps of item generation in JAIMAR, will be presented.

\section{Methods}

19 mothers who have children with autoinflammatory disease (8 FMF, 5 Behcet, 4 PFAPA, 1 HIDS, 1 TRAPS) and their children greater than 7 years old were enrolled in this study. Data were collected using both a demographic data form and a semi-structured interview form. The study was performed on individual patient face-to face interview. Data were collected by using both a demographic data form and a semi-structured interview form. Data analysis by grounded theory and N Vivo 10 software.

\section{Results}

Unknowing the time of attack, lifelong illness, difficulties in diagnosis and exposure to the other parts of the

${ }^{1}$ School of Nursing, Gulhane Medical Military Academy, Ankara, Turkey Full list of author information is available at the end of the article body were described as the worst parts of the illness. In addition to physical factors such as cold and fatigue, psychological factors such as overexcitement, worry and happiness were stated to be in the triggering factors of the attacks. Although decrease in attacks after treatments were stated, lifelong drug addiction and its side effects were told to be the most worrying aspects. Problems at school (absenteeism, loss of performance, fear of having attack at school and bad peer relations) were explained as the biggest difficulties affecting the quality of life. Problems with friends, precocity, and extreme expressions such as depression/wanting to die due to back pain were to be the in the emotional difficulties.

\section{Conclusion}

These results provide an evidence based data for the assessment of children with autoinflammatory disease by several domains including physical, emotional and social aspects as well as treatment protocols. With this regard there is a need to develop a multidimensional instrument to measure important aspects of the illness gained from these results.

\section{Disclosure of interest}

None declared.

\section{Authors' details}

'School of Nursing, Gulhane Medical Military Academy, Ankara, Turkey. 2Department of Biostatistics, Gulhane Medical Military Academy, Ankara, Turkey. ${ }^{3}$ Department of Child and Adolescent Psychiatry, Gulhane Medical Military Academy, Istanbul, Turkey. ${ }^{4}$ Paediatric Nephrology and

Rheumatology Unit, Hacettepe University, Ankara, Turkey. ${ }^{5}$ Pediatric Rheumatology Unit, Kremlin, Bicetre, France. ${ }^{6}$ Pediatric Rheumatology Unit, University of Amsterdam, Utrecht, TheNetherlands. ${ }^{7}$ Rheumatology Unit, Instituto Giannina Gaslini, Genoa, Italy. ${ }^{8}$ Pediatric Rheumatology Unit, Gulhane Medical Military Academy, Ankara, Turkey. 
- Convenient online submission

- Thorough peer review

- No space constraints or color figure charges

- Immediate publication on acceptance

- Inclusion in PubMed, CAS, Scopus and Google Scholar

- Research which is freely available for redistribution 